
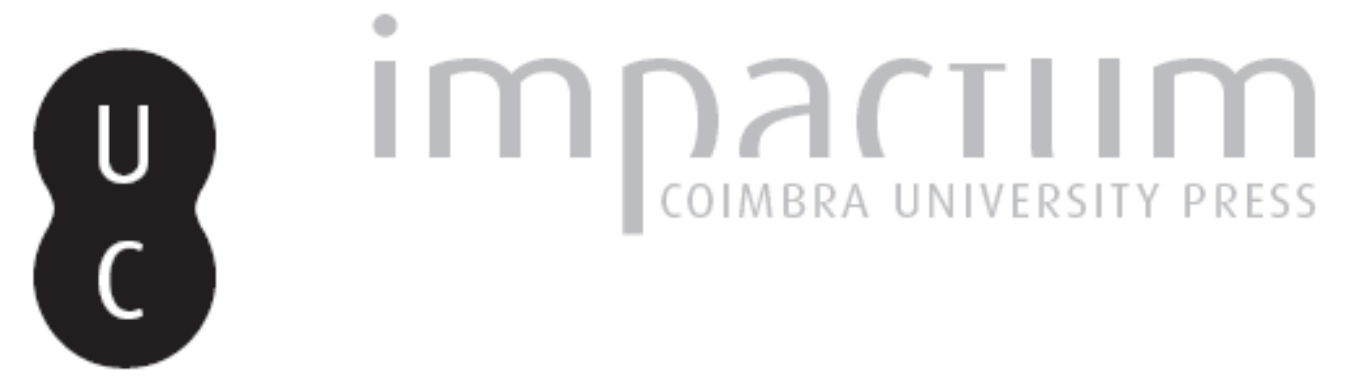

\title{
O território português nos inícios do século XIV: espaço e narrativa nos relatos do reinado de D. Dinis
}
Autor(es):
Valdaliso, Covadonga
Publicado por: Centro de História da Sociedade e da Cultura
URL
persistente:
URI:http://hdl.handle.net/10316.2/39385
DOI:
DOI:http://dx.doi.org/10.14195/1645-2259_13_3

Accessed : $\quad$ 26-Apr-2023 11:26:15

A navegação consulta e descarregamento dos títulos inseridos nas Bibliotecas Digitais UC Digitalis, UC Pombalina e UC Impactum, pressupõem a aceitação plena e sem reservas dos Termos e Condições de Uso destas Bibliotecas Digitais, disponíveis em https://digitalis.uc.pt/pt-pt/termos.

Conforme exposto nos referidos Termos e Condições de Uso, o descarregamento de títulos de acesso restrito requer uma licença válida de autorização devendo o utilizador aceder ao(s) documento(s) a partir de um endereço de IP da instituição detentora da supramencionada licença.

Ao utilizador é apenas permitido o descarregamento para uso pessoal, pelo que o emprego do(s) título(s) descarregado(s) para outro fim, designadamente comercial, carece de autorização do respetivo autor ou editor da obra.

Na medida em que todas as obras da UC Digitalis se encontram protegidas pelo Código do Direito de Autor e Direitos Conexos e demais legislação aplicável, toda a cópia, parcial ou total, deste documento, nos casos em que é legalmente admitida, deverá conter ou fazer-se acompanhar por este aviso.

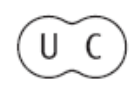



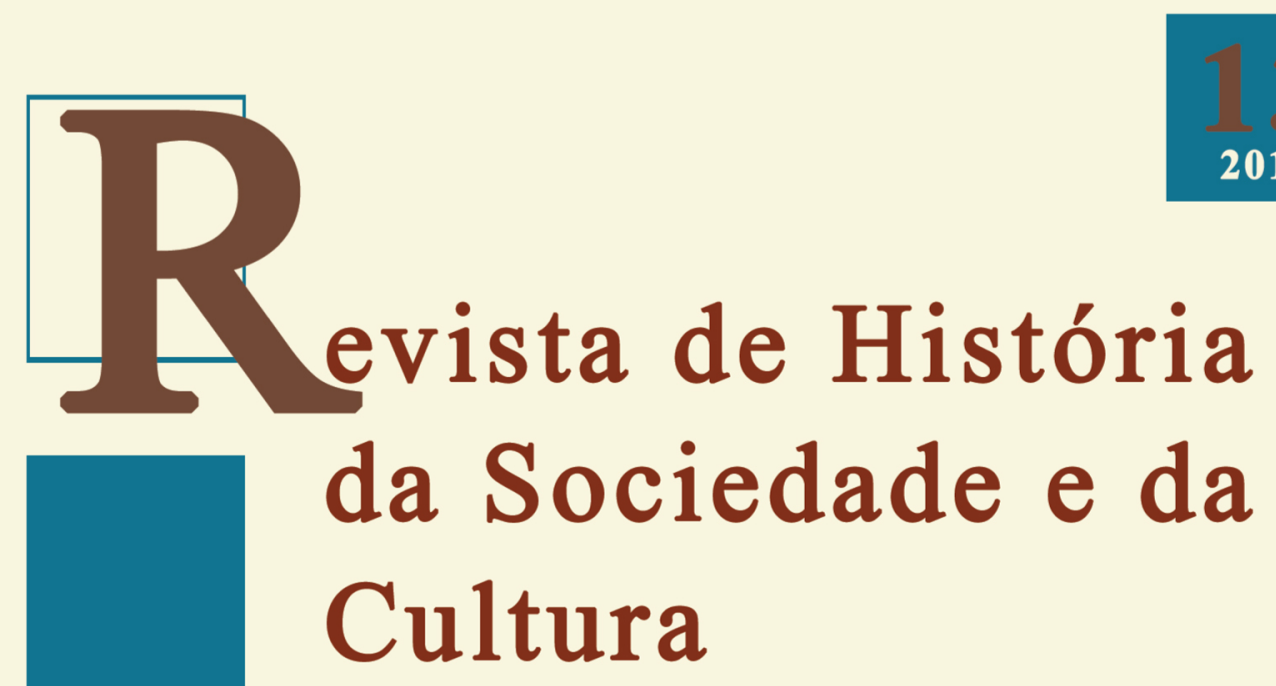

2013

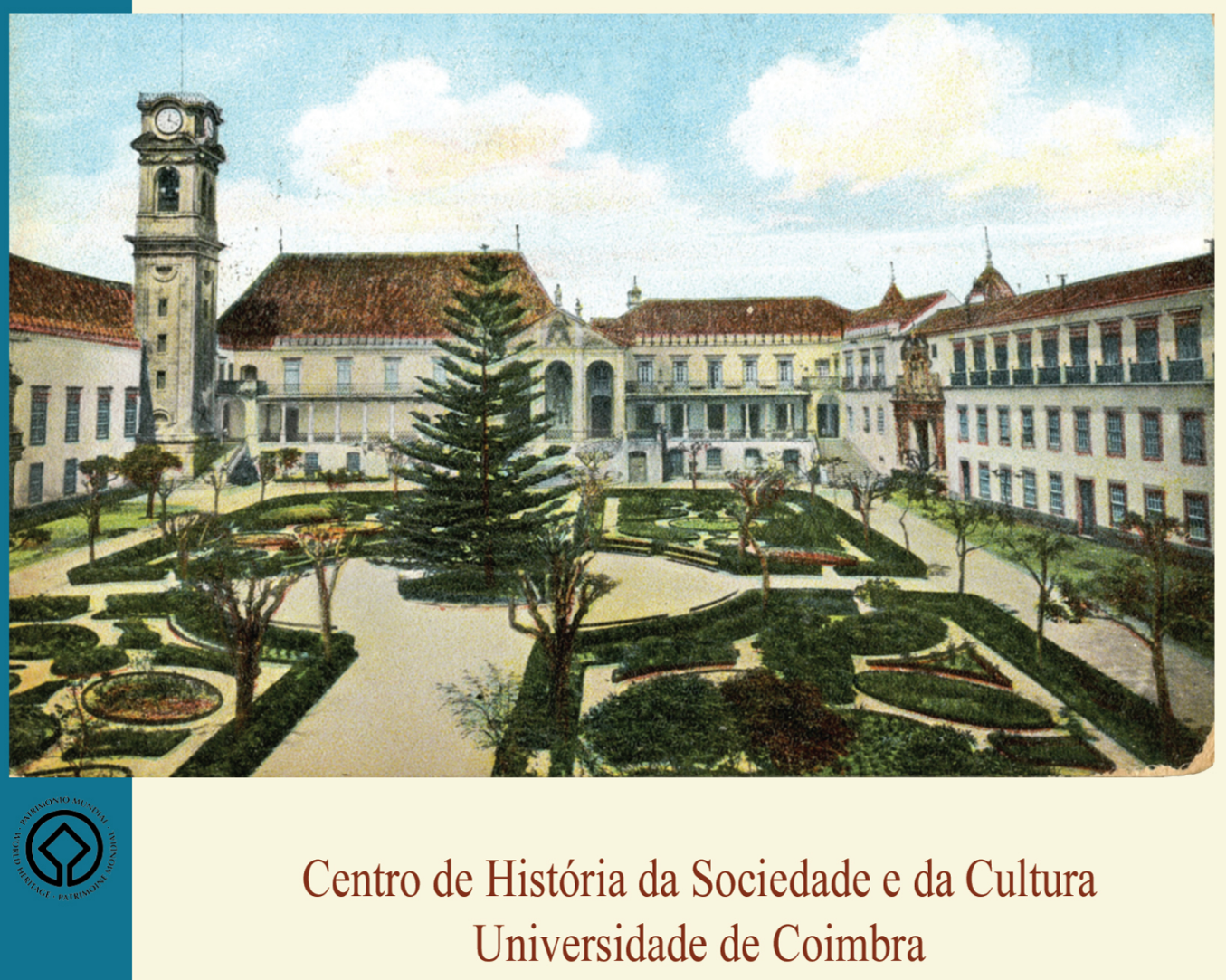

Coimbra 


\title{
O território português nos inícios do século XIV. Espaço e narrativa nos relatos do reinado de D. Dinis*
}

\author{
Covadonga Valdaliso \\ Centro de História da Sociedade e da Cultura (Universidade de Coimbra) \\ Centro de História da Faculdade de Letras (Universidade de Lisboa) \\ covaldaliso@hotmail.com \\ Texto recebido em /Text submitted on: 31/05/2013 \\ Texto aprovado em / Text approved on: 29/09/2013
}

\section{Resumo/Abstract:}

Pretende-se neste artigo analisar a imagem do território político português na primeira metade do século XIV a partir da análise de três textos narrativos escritos no período que relatam o reinado de D. Dinis: a Vida e milagres de Dona Isabel, o Título VII do Livro de Linhagens do Conde Dom Pedro e o capítulo DCCXIX da Crónica de Espanha de 1344. Parte-se da ideia de que estas fontes fornecem dados conscientes, e portanto criam um território simbólico, condicionado pela intencionalidade dos escritos e com uma funcionalidade narrativa e política.

This paper aims to study the image of the political Portuguese territory in the first half of the 14th century. The analysis is based on three narrative texts written on the period and relating D. Dinis' Kingdom: Vida e milagres de Dona Isabel, Título VII of the Livro de Linhagens do Conde Dom Pedro and chapter DCCXIX of the Crónica de Espanha de 1344. The study is based on the idea that data provided by these sources were consciously chosen, and thus created a symbolic territory, conditioned by the intention of the writings and by their narrative and political functionality.

Palavras chave/Keywords:

Portugal; Território; Representação; Historiografia; D. Dinis.

Portugal; Territory; Representation; Historiography; D. Dinis.

* Este trabalho foi realizado no âmbito do projeto "Lugares de poder e configuração política do reino português (1279-1383)”, financiado pela FCT (SFRH/BDP/73087/2010). Agradeço a Filipe Alves Moreira, pela ajuda na localização e seleção das fontes narrativas. 
A distribuição espacial da população portuguesa nos fins do século XIII revela a imagem seguinte: «A região mais povoada de Portugal era (...) o Entre-Douro-e-Minho. Seguiam-se-lhe a Estremadura, a Beira e Trás-os-Montes. A longa distância destas se posicionava a distribuição populacional no Alentejo. Predominavam, por todo o País, os pequenos aglomerados populacionais. A mais forte urbanização sentia-se em Lisboa e nos seus arredores» ${ }^{1}$. Esta é uma descrição construída a posteriori, a partir da análise dos dados fornecidos por fontes indiretas, de índole militar, fiscal ou religiosa ${ }^{2}$. Com a escassa informação que resta do período medieval têm-se construído outras imagens do território, baseadas na distribuição da propriedade da terra, na administração, nos lugares onde existiam residências régias, nos itinerários dos monarcas,... Mas é difícil estabelecer se essas imagens correspondem à imagem que se tinha, nesse período, do espaço político. O presente artigo pretende esboçar uma aproximação a esta última imagem a partir da análise de três textos narrativos que relatam o reinado de D. Dinis: a Vida e milagres de Dona Isabel, o Título VII do Livro de Linhagens do Conde Dom Pedro e o capítulo DCCXIX da Crónica de Espanha de $1344^{3}$.

As fontes narrativas diferenciam-se bastante das documentais. Por um lado, a narratividade condiciona a sua análise; por outro, oferecem informação que outras fontes não contêm. Do ponto de vista da teoria narratológica, um relato deve construir linhas temporais para ordenar uma trama de factos ou história ${ }^{4}$. Nos relatos historiográficos a trama de factos já existe, e compõe-se de uma série de unidades de tempo e espaço - que se podem identificar com os "cronótopos" de Bakhtin - que constitui a base

1 COELHO, Maria Helena da Cruz - Os homens ao longo do tempo e do espaço in OLIVEIRA MARQUES, António H. de - Nova História de Portugal: Portugal em Definição de Fronteiras (1096-1325). Lisboa: Presença, 1987, p. 183. A partir de OLIVEIRA MARQUES, António H. de - A população portuguesa nos fins do século XIII in Ensaios de História Medieval Portuguesa. Lisboa: Ed. Vega, 1980 (2ª ed.), p. 67-73.

2 COELHO, Maria Helena da Cruz - Os homens ao longo do tempo e do espaço, cit., p. 166.

3 Segundo a numeração da edição consultada: LINDLEY CINTRA, Luís Filipe - Crónica Geral de Espanha de 1344, 4 vols., Lisboa: Academia Portuguesa de História/Imprensa Nacional-Casa da Moeda, 2009.

4 Sobre o tempo e o espaço narrativos, GÓMEZ REDONDO, Fernando - Curso de iniciación a la escritura narrativa. Alcalá de Henares: Universidad de Alcalá, 2008. 
do relato ${ }^{5}$. Assim, se os autores de ficção criam umas linhas temporais e uns marcos espaciais para referenciar os factos e projetá-los, os historiadores partem de uma trama, construída a partir da seleção dos acontecimentos a narrar, e confecionam o relato com base nessa trama. Em consequência, as linhas temporais não são aleatórias, e o espaço está predeterminado. Porém, quando o historiador é coetâneo dos factos há uma escolha consciente da matéria a narrar, bem como dos momentos e dos lugares que irão fazer parte da narrativa. Dessa escolha deriva uma imagem propositada, que é imortalizada no relato.

Os três relatos escolhidos para este estudo foram escritos no reinado de D. Afonso IV e os seus autores - o primeiro anónimo e o segundo o Conde de Barcelos - viviam no tempo que depois narraram. Parte-se da hipótese de que ambos criaram nas suas narrativas imagens do território político; i.e., construíram um território simbólico, com significado dentro das suas narrativas. Portanto, os textos não mostram a imagem que se tinha no período, mas sim imagens criadas no período. Estas imagens estavam condicionadas por uma série de fatores (motivações, objetivos, natureza, função dos escritos) que explicam o seu porquê, e assim revelam os seus significados. São imagens subjetivas, conscientes e propositadas. Cada uma delas obedece a uma intencionalidade diferente, mas as coincidências não derivam exclusivamente do facto de narrarem o mesmo período. Direta ou indiretamente ligados à monarquia, estes relatos aproximam-nos da imagem que o poder tinha do reino. Comecemos por ver qual era essa imagem no escrito sobre a Rainha Isabel.

Tem sido muito discutido se a Vida e milagres de Dona Isabel se pode considerar um escrito historiográfico. Esta discussão faz parte do debate sobre a especificidade da hagiografia enquanto género literário ou género histórico, e sobre a sua validade documental ${ }^{6}$. O texto, que narra alguns

5 BAKHTIN, Mikhail - Questões de literatura e de estética: a teoria do romance. São Paulo: Unesp/Hucitec, 1993 (BAKHTIN, Mikhail - Voprosy literatury i estetiki. Moscow: Khudozhestvennaia literatura, 1975).

6 SOBRAL, Cristina - O modelo discursivo hagiográfico in LARANJINHA, Ana Sofia e MIRANDA, José Carlos Ribeiro (org.) - Modelo: Actas Do V Colóquio da Secção Portuguesa da Associação Hispânica de Literatura Medieval. Porto: Departamento de Estudos Portugueses e Estudos Românicos da Faculdade de Letras da Universidade do Porto, 2005, p. 97-107. 
episódios da vida da Rainha Santa e refere vários milagres que lhe foram atribuídos, antes e depois de morta, numa clara tentativa de demonstrar a sua santidade, possui os traços distintivos do género hagiográfico, quer no nível textual - discurso panegírico com enumeração de virtudes -, quer no extratextual - intencionalidade edificante e objetivo de promover o culto ${ }^{7}$. Porém, pelo facto da personagem central ser uma rainha, e do relato conter episódios históricos de conteúdo político, com uma certa preocupação pela verdade histórica e uma particular atenção aos dados genealógicos e espácio-temporais, bem como às intervenções de Dona Isabel nos conflitos, tem-se falado dum texto "híbrido" ; uma "crónica hagiográfica" escrita segundo algumas das regras da biografia cortesã - se bem que com elementos próprios das "vidas" de personagens ligadas à corrente franciscana - mais original em Portugal do que no contexto europeu, e difícil de encaixar na categoria hagiográfica, mesmo quando se estrutura segundo o modelo destas obras 9 . Aceite, portanto, a autonomia do escrito, este pode ser definido como um discurso hagiográfico, condicionado pela sua função - que determina os seus conteúdos - e estruturado narrativamente nas quatro unidades características deste tipo de discurso (infância, maturidade, morte e culto), mas diferenciado

7 SOBRAL, Cristina - O modelo discursivo hagiográfico, cit., p. 98.

8 MACHADO, Ana M. - Livro que fala da Boa Vida que fez a Rainha de Portugal, D. Isabel in LANCIANI, Giulia e TAVANI, Giuseppe (coord.) - Dicionário de Literatura Medieval Galega e Portuguesa. Lisboa: Caminho, 1993, p. 418.

9 «Poder-lhe-íamos talvez chamar-lhe uma "crónica hagiográfica", pois o facto de evocar a vida de uma grande senhora leiga fá-la seguir algumas regras da biografia cortesã; mas é necessário insistir no carácter exemplar, de construção da santidade, que manifesta, pois este é singularmente semelhante ao de outras vidas de grandes nobres ligadas aos franciscanos. Aqui parece-nos residir precisamente a sua maior importância, nem sempre suficientemente realçada pelo enfoque de que tem sido alvo, excessivamente literário e restringido a Portugal. De facto, os traços biográficos de Isabel de Aragão são completamente "versados" no modelo de vida que percorre um certo número de vidas de grandes damas da corte que optam pela vivência franciscana, entre as quais avulta Isabel da Hungria, tia-avó da Santa. As circunstâncias reais da vida das várias santas reflectem-se em diferentes enredos; porém, sempre presente, está uma das propostas franciscanas de concretização prática do ideal de pobreza, por parte de grandes senhoras temporais. Entre as várias, precisamente aquela que propõe a via intermédia». ROSA, Maria de Lurdes - A santidade no Portugal medieval: Narrativas e trajectos de vida. Lusitania sacra, 2a série. 13-14 (2001-2002), p. 425. O extenso artigo (p. 369-450) oferece uma ampla discussão sobre a temática, e dedica várias páginas (424-429) à obra sobre a Rainha. 
do discurso historiográfico apenas no objetivo, e não na conceção do real ou do passado ${ }^{10}$.

A autoria e a data da escrita têm sido também assuntos amplamente tratados. Os especialistas coincidem em que o manuscrito original da Vida terá sido escrito pouco depois da morte da Rainha e por alguém próximo a ela e relacionado com o mosteiro de Santa Clara, onde provavelmente foi preservado. Concretamente, a datação interna do texto indica que foi escrito antes de 1337, data da morte do irmão da Rainha, Frederico, de quem se diz "que hora chamão Rey em Sicilia"". Perdido esse original, a cópia mais antiga conservada data do ano 1592, estava no mosteiro de Santa Clara e hoje conserva-se no Museu Machado de Castro de Coimbra. Para alguns autores o título desta cópia - Livro que fala da boa vida que fez a Rainha de Portugal, Dona Isabel, e de seus bons feitos e milagres em sa vida e depois da morte - foi tomado do original; para outros, criado depois $^{12}$. No percurso que levou da primeira versão do Livro até a cópia quinhentista somaram-se ao texto alguns acrescentos finais que referem acontecimentos posteriores à data da escrita. É difícil estabelecer quando finalizava o original: muitos dos episódios narrados na última parte do texto, dedicada ao "culto", identificam-se como "milagres", de tal maneira que revelam uma consciência da santidade da protagonista que até essa altura no texto não aparece explicitada ${ }^{13}$; mas os "milagres" começam a aparecer desde que o corpo é sepultado, e provavelmente já no original, anterior a 1337, o autor utilizava essa linguagem de "santidade" na última parte da Vida, que depois foi ampliada.

A edição da Vida e milagres de Dona Isabel do Padre Francisco Brandão, publicada no Apêndice do volume VI da Monarquia Lusitana, em 1672, e titulada Relaçam da Vida da Gloriosa Santa Isabel rainha de Portugal,

${ }^{10}$ SOBRAL, Cristina - O modelo discursivo hagiográfico, cit., p. 100, 101 e 104.

${ }^{11}$ FIGANIÈRE, Frederico Francisco de la-Memórias das rainhas de Portugal. Lisboa, 1859 , p. 257 e 258.

12 «Esta obra, que terá sido escrita pelo próprio confessor da Rainha, o mendicante Frei Salvado Martins, chegou até nós apenas numa versão quinhentista, sendo o título acima indicado uma reconstituição. No entanto, além de alguns acrescentos no fim do texto, o grosso da obra permanece fiel ao original e constitui portanto um rico material de trabalho». ROSA, Maria de Lurdes - A santidade no Portugal medieval, cit., p. 424.

${ }^{13}$ MACHADO, Ana M. - Livro que fala da Boa Vida, cit,. p. 417. 
parece baseada no manuscrito de $1592^{14}$. Posteriormente apareceram mais duas edições: a primeira representa uma tentativa de reconstruir a linguagem original do texto ${ }^{15}$, e a segunda faz parte duma tese de mestrado inédita ${ }^{16}$. No presente trabalho remete-se à edição do Padre Brandão para simplificar a consulta ${ }^{17}$. Os "milagres" posteriores a 1337 não serão tidos em conta porque, pelo facto de não fazerem parte do escrito original, também não transmitem a imagem do reino que o autor criou na sua escrita.

A origem dinástica, o nascimento e a infância de Dona Isabel ocupam as primeiras páginas da Vida, que transcorrem na Coroa de Aragão ${ }^{18}$. A primeira data que aparece no texto é a do nascimento da Rainha «andaua a Era de Cezar em mil \& iij. \& noue annos» - e a segunda a da morte do rei D. Afonso III de Portugal - «xiij. dias de Feuereiro Era M III. \& XVII annos» - que marcou o início do reinado de D. Dinis. A segunda parte do discurso, dedicada à maturidade da Rainha, não segue uma ordem cronológica. Embora apareçam algumas datas, como a do nascimento do futuro Afonso IV, a morte de D. Dinis e a inundação da igreja de Santa Clara,

${ }^{14}$ «O autor da relação se não declara mas dela se colige que é muito antiga, e muito próxima à morte da Santa Rainha. No princípio do livro está pintada a imagem da Santa vestida com o hábito, cordão, manto e véu da Ordem de Santa Clara. Tem na mão direita um crucifixo, e na cabeça uma coroa de espinhos. Aos seus pés estão lançados uma coroa, e ceptro reais, com a letra seguinte: Crux, et spinea corona Domini me, sceptrum, et corona mea». BRANDÃO, Francisco - Relaçam da Vida da Gloriosa Santa Isabel rainha de Portugal in Monarquia Lusitana, vol. VI. Lisboa: Imprensa Nacional-Casa da Moeda, 1980 (reimpressão da $1^{a}$ edição, de 1672), p. 495. Esta descrição coincide com a imagem do manuscrito de 1592.

${ }^{15}$ NUNES, Joaquim José - Vida e milagres de Dona Isabel rainha de Portugal. Texto do século XIV restituído à sua presumível forma primitiva, separata do Boletim da Classe de Letras da Academia das Ciências de Lisboa, n. ${ }^{\circ}$ 13. Coimbra: Imprensa da Universidade, 1921, p. 1293-1384.

${ }^{16}$ MONTES, Maria Isabel da Cruz - Vida e milagres de Dona Isabel rainha de Portugal (edição e estudo). Lisboa: Faculdade de Ciências Sociais e Humanas da Universidade Nova de Lisboa, 1999 (Dissertação de mestrado policopiada).

${ }^{17}$ Sobre a tradição manuscrita e as edições DIAS, Isabel Rosa - A narrativa da vida e milagres da Rainha Santa Isabel: testemunhos e edições in CAÑAS MURILLO, Jesús, GRANDE QUEJIGO, Francisco Javier e ROSO DÍAZ, José (coord.) - Medievalismo en Extremadura. Estudios sobre literatura y cultura hispânicas en la Edad Media. Cáceres: Universidad de Extremadura, 2009, p. 279-292. Uma atualização deste artigo no trabalho, ainda inédito, da mesma autora: "La biographie médiévale de la reine Sainte Isabel du Portugal (1271-1336): les témoins et les éditions".

${ }^{18} \mathrm{Na}$ edição de Francisco Brandão a infância da Rainha ocupa as páginas 495 a 499 e a maturidade as páginas 499 a 522 . 
o autor estrutura a narrativa a partir de temáticas ${ }^{19}$. Dentro destas temáticas interessam especialmente aos historiadores as dedicadas ao enfrentamento entre D. Dinis e o infante Afonso, a intervenção de D. Dinis e D. Isabel como intermediadores no contexto dos problemas entre Castela e Aragão, a rebelião do herdeiro e a morte de D. Dinis; mas no texto intercalam-se com outras: a morte da filha Constança, a fundação de Santa Clara, e diferentes passagens que sublinham as virtudes cristãs da Rainha e descrevem o seu carácter, ou os seus hábitos quotidianos. A terceira parte dedica-se à morte da Rainha e às sete jornadas de viagem do corpo de Estremoz a Coimbra. A quarta e última parte se diferencia pouco no relato da anterior, e se compõe de vinte e um episódios milagrosos, cinco deles protagonizados pela Rainha em vida e dezasseis depois de morta; alguns claramente posteriores à data de escrita do original ${ }^{20}$. Na narração da maior parte destes episódios faz-se referência aos "instrumentos" que o autor do escrito estava a consultar, aparecem os nomes das testemunhas e dos tabeliães, e às vezes também são referidas as datas dos documentos ${ }^{21}$.

A representação do espaço na Vida de Dona Isabel está, logicamente, condicionada por todas as características do texto que acabaram de ser indicadas $^{22}$. Há no escrito aproximadamente uma centena de referências a

${ }^{19}$ «No sintagma da maturidade, o cumprimento do(s) modelo(s) de santidade demonstra-se estruturando a narrativa segundo um modo temático ou segundo um modo cronológico. O primeiro narra eventos destinados a mostrar que o santo possuía uma série de virtudes, sendo estas enunciadas serialmente como subordinantes dos eventos». SOBRAL, Cristina - O modelo discursivo hagiográfico, cit., p. 101.

${ }^{20}$ A morte e a translação do corpo ocupam as páginas 522 a 525 da edição citada; os episódios relacionados com o culto começam na página 525. Os dez primeiros são episódios que aconteceram depois da morte da Rainha, os cinco seguintes fazem referência a sucessos que aconteceram quando a Rainha ainda era viva, e os seis seguintes são de novo posteriores à sua morte.

${ }^{21}$ Um documento semelhante, encontrado no cartório de Santa Clara e datado em 1336 - ano da morte da Rainha -, referido em FIGANIÈRE, Frederico Francisco de la-Memórias das rainhas de Portugal, cit., p. 260 e 261.

${ }^{22}$ Para além da bibliografia já citada, outros estudos fundamentais sobre o texto e sobre a Rainha em VASCONCELLOS, A. Garcia Ribeiro de - Evolução do culto de Dona Isabel de Aragão, esposa do Rei Lavrador D. Dinis de Portugal (a Rainha Santa), t. 1. Coimbra: Imprensa da Universidade, 1894; MUÑOZ FERNÁNDEZ, Ángela - Santa Isabel Reina de Portugal: una infanta aragonesa paradigma de religiosidad y comportamiento femenino en el Portugal bajomedieval in Actas das II Jornadas Luso-Espanholas de História medieval, vol. III. Porto: Instituto Nacional de Investigação Científica, 1987, p. 1127-1143; ROSA, Maria de Lurdes - Mendicantes e redes de piedade feminina (1278-1336): três donas em 
lugares, mas uma terceira parte delas corresponde a Coimbra, o lugar onde a Vida se escreveu, onde estavam o mosteiro de Santa Clara e a sepultura de Dona Isabel, e onde a Rainha passou os seus últimos anos de vida. No total, o texto documenta vinte e cinco localidades. Coimbra é seguida por Lisboa, Estremoz - lugar em que a Rainha faleceu -, Santarém e Sintra em número de citações. Algumas destas localidades não se relacionam diretamente com a Rainha: fala-se do bispo de Guarda, do abade de Alcobaça, de uma mulher de Lamego. Outros lugares aparecem associados a determinados acontecimentos: Bragança foi a localidade onde os castelhanos que tinham acompanhado a Rainha na sua viagem a Portugal regressaram a Castela; Trancoso foi a vila onde casou com D. Dinis. Há também localidades ligadas a instituições religiosas, como Almoster ou Odivelas, lugar onde foi enterrado o rei. Sintra, Torres Novas, Óbidos e Leiria aparecem como terras da Rainha.

Quando as localidades em que se documenta a presença da Rainha são representadas num mapa, chama a atenção a concentração de lugares próximos a Lisboa (Lumiar, Chelas, Odivelas, Loures); e também a ausência de referências a amplas áreas do país. Aparentemente, Dona Isabel nunca foi ao Algarve, e pouco se refere do Norte ou do Alentejo. O espaço da narração da Vida desde que a Rainha casa até que morre é fundamentalmente a região centro-litoral, e especialmente o eixo Coimbra-Santarém-Lisboa; lugares em que havia paços que serviam como residências semipermanentes da Corte. Dos percursos seguidos nas deslocações a Vida diz pouco: no episódio do ermitão a Corte passava por Pontével quando ia de Santarém para Lisboa, mas a Rainha desviou-se para Azambuja ${ }^{23}$; numa outra ocasião, indo de Coimbra ao Porto, passou por Arrifana ${ }^{24}$. Mas há um episódio em que o texto

busca de religiosidade própria e uma Ordem que descobre a sua «santa» in RODRIGUES, Ana Maria e JORGE, Ana Ma - História Religiosa de Portugal, vol. I. Lisboa: Círculo de Leitores, 2000, p. 470-480; e ANDRADE, Maria Filomena - Rainha Santa, mãe exemplar: Isabel de Aragão. Lisboa: Círculo de Leitores, 2012.

${ }^{23}$ «Vindo esta Rainha de Santarem para Lisboa com ElRey Dom Dinis, apartandose ella de hum lugar a que chamão Ponteual, \& vinha para hua villa que dizem Azambuja», p. 499 e 500 .

${ }^{24}$ «Vijndo esta Rainha de Coimbra pera a Cidade do Porto, recodio ao caminho hua molher em hum logar a que dizem Arrifana», p. 531. 
desenha os movimentos das personagens mais detalhadamente: o dedicado à rebelião do herdeiro ${ }^{25}$.

O espaço é no relato da rebelião um elemento fulcral. De uma perspetiva narratológica isto faz sentido: pelo facto de no escrito apenas existirem referências de temporalidade, são precisas referências espaciais para ajustar as significações a uma ordem externa que as faça compreensíveis ${ }^{26}$. A ordem é o território do reino; as personagens, peças de xadrez que o autor coloca em determinados lugares, de tal maneira que o deslocamento de uma provoca os deslocamentos das outras ${ }^{27}$. Assim, o espaço narrativo, esse que se constrói para dar corpo à narração, atua aqui também como o elemento que confere sentido ao que é narrado. E isto acontece porque remete a um espaço real, que o destinatário do texto - de um relato escrito em português - conhece $^{28}$. As imprecisões temporais são compensadas pelas espaciais ${ }^{29}$. O reino é o palco e as suas localidades referentes para as diferentes cenas que se sucedem dentro duma mesma narrativa, dedicada a uma temática - o labor intercessor da Rainha.

A análise dos diferentes episódios da Vida que documentam as movimentações de Dona Isabel, e também de outras personagens, revela o valor simbólico do espaço no texto ${ }^{30}$. Em todos os casos, a funcionalidade

${ }^{25} \mathrm{Na}$ edição consultada p. 503-507.

${ }^{26}$ A única referência ao tempo real deduz-se do facto do futuro Pedro I já ter nascido: «E vindo já o dito Rey Dom Affonso sendo Infante por o Reyno em sa parte com sa mulher de mandado delRey seu Padre fazendo morada na Cidade de Coimbra por ir em romaria a S. vicente de Lisboa, \& leixou a Infante sa mulher, \& o Infante Dom Pedro seu filho, que já em aquele tempo era nado em Coimbra» (p. 503 e 504).

${ }^{27}$ «E desde que complio sua romaria, tornandose de Lisboa para hua Villa que dizem Sintra, ElRey seu padre, \& e a Rainha sa madre vinhaõse de Santarem a Lisboa. (...) Estando o dito Infante em Sintra, elRey seu padre chegou ao Lumiar a hua legoa de Lisboa, \& soube como o Infante era em Sintra. (...) Que ante por tempo que elRey a Sintra, hu o Infante era chegasse, ante o Infante soube, \& partiose dalli, \& veose para aquelle logo hu ficara a Rainha sa madre» (p. 504).

${ }^{28}$ Diversos autores sublinham o facto de a Vida ser a primeira hagiografia escrita em português. Parece claro que o texto foi concebido para ser lido e conservado em Santa Clara de Coimbra, e as traduções ao latim são muito tardias.

${ }^{29}$ «Acabo de tempo sendo ElRey Dom Dinis em Santarem, conselharomno que partisse de si a Rainha» (p. 504); «Hauiendo adiante discordia antre ElRey, \& o Infante seu filho, El Rey foi cercar a cidade de Coimbra que o Infante seu filho já tinha para mantimento seu e dos seus» (p. 506).

${ }^{30}$ A ida da Rainha para Alenquer, por exemplo: «El Rey segundo aquel conselho, mandou à Rainha para hũa Villa a que dizem Alanquer (...) e a Rainha seendo bem obediente, 
narrativa do espaço no escrito relaciona-se com a intencionalidade do relato. Na Vida e milagres de Dona Isabel os episódios, temporalmente abstratos por - propositadamente - não terem sido datados, são projetados num espaço real conhecido e reconhecível. O pretérito ao qual pertencem os acontecimentos narrados convive no relato com o presente do território palpável, onde são custodiados os restos da Rainha e onde ainda existem os lugares onde ela esteve. Os motivos que levaram o autor a fazer esta escolha - indefinição do tempo e concretização do espaço - relacionam-se com a natureza hagiográfica do discurso. Porém, o que importa é que essa escolha foi feita de maneira consciente e para dotar a história de um significado.

Algo similar acontece com o Título VII do Livro de Linhagens do Conde Dom Pedro ${ }^{31}$. Este texto desenha nas primeiras páginas uma geografia pretérita que, mesmo se toma como ponto de partida a herança deixada pelo Conde Dom Henrique ao seu filho Afonso Henriques, "de Astorga a Coimbra" 32 , acaba por se centrar na área meridional, onde tiveram lugar as principais batalhas do reinado - Ourique -, e onde estavam as terras conquistadas pelo monarca, i.e., Lisboa, Sintra, Almada, Palmela, Alcácer, Beja, Évora, Moura, Serpa. Ao longo do relato dos primeiros reinados são frequentemente citados os lugares de enterramento dos membros da família real, símbolos da progressão territorial, em direção ao Sul, do reino. A maioria dos corpos foram sepultados em Santa Cruz de Coimbra, mas o Conde Dom Henrique tinha sido enterrado em Braga, e os restos mortais

\& estando em aquel logar, souberom os Caualeiros de Portugal que a ella hauião feita omenagem por castelos que tinhão, (...) \& vierom alguns aquelle logar dizendo que a elles fora dito, que ElRey a apartara de sa casa» (p. 505).

${ }^{31}$ MATTOSO, José (ed.) - Livro de Linhagens do Conde D. Pedro in Portugaliae Monumenta Historica. Nova Série. Lisboa: Academia das Ciências, 1980. Todas as citações do texto remetem a esta edição, que reconstitui a refundição de 1380-1383; mas considera-se que este título foi da autoria do Conde. Sobre a obra MATTOSO, José - Livros de Linhagens in LANCIANI, Giulia e TAVANI, Giuseppe (coord.) - Dicionário de Literatura Medieval Galega e Portuguesa, cit., p. 419-421, SIMÕES, M. - Pedro de Portugal, Conde de Barcelos in LANCIANI, Giulia e TAVANI, Giuseppe (coord.) - Dicionário de Literatura Medieval Galega e Portuguesa, cit., p. 521-523 e FERREIRA, Ma do Rosário-A estratégia genealógica de D. Pedro, Conde de Barcelos, e as refundições do Livro de Linhagens. e-Spania 11 (2011) (http://e-spania.revues.org/20273 consultado em 2013.05.27).

32 «Quando morreo em Astorga, chamou seu filho dom Afonso Anriquez, e disse-lhe: "Filho, toda esta terra que te eu leixo des Astorga ataa Coimbra, nom percas ende uu palmo, ca eu a gaanhei com gram coita», p. 123. 
dos reis D. Afonso II e D. Afonso III ficaram em Alcobaça. Quando chega ao relato do reinado de D. Dinis, o Livro de Linhagens cita o mosteiro de Santa Clara de Vila do Conde - lugar de enterramento de Afonso Sanches -, a cidade de Lisboa, as localidades que passaram a fazer parte de Portugal (Sabugal, Castelo Rodrigo, Almeida, Vila Maior, Alfaiates), e o mosteiro de Odivelas - lugar de enterramento do rei. O território é, portanto, definido a partir de acontecimentos políticos que o ampliaram, e de pontos simbólicos diretamente relacionados com a dinastia régia (Braga, Coimbra, Alcobaça, Odivelas) que materializam a conexão entre o espaço e a monarquia. Mas, de novo, encontramos uma narrativa espacial no episódio do enfrentamento entre o rei e o seu filho Afonso.

Desta vez o tempo sim é referente no discurso: três sucessos relativos à primeira fase do conflito são detalhadamente datados ${ }^{33}$, e também um quarto relativo à segunda ${ }^{34}$. Assim, tempo e espaço atuam juntamente como referentes e, em conjunto com os factos, atingem o principal objetivo da historiografia: o registo do passado. Este esquema básico (data-lugar-facto), característico dos anais, é no discurso do Título VII do Livro de Linhagens desenvolvido narrativamente ${ }^{35}$. Destaca-se, dentro desta narração, o pequeno relato do cerco de Coimbra ${ }^{36}$. O autor do texto aparece neste relato

${ }^{33}$ «E o ifante dom Afonso soube isto e tomou-lhe a cidade de Coimbra vespora de Janeiro depois de comer, era de mil CCC L IX anos. Em outro dia de Janeiro tomou Monte Moor o Velho, rompente o alvor, e esto foi na era de mil CCC LX. (...) El rei dom Denis soube que jazia sobre a vila de Guimarães, e el veo-se deitar sobre Coimbra. E chegou i o primeiro dia de Março, em Coreesma», p. 130.

${ }^{34}$ «E depois esto, houve este ifante, na era de mil CCC LX II, no mes de Fevereiro, outra vez gram desavença com el rei seu padre, em Santarem», p. 131.

${ }^{35}$ «E foi-se e tomou a Feira e o castelo de Gaia e a torre da menagem do Porto, e foi-se deitar sobre a vila de Guimarães. E guardava a vila e o castelo uu cavaleiro que chamavam Meem Rodriguez de Vasconcelos, e defendeo-lha mui bem» (p. 130); «E levantarom-se em volta, de ua parte e da outra, e matarom os d'el rei uu boo cavaleiro, que havia nome Fernam Gomez de Carvalho, que era vassalo do ifante (...)» (p. 131).

${ }^{36}$ «El rei dom Denis soube que jazia sobre a vila de Guimarães, e el veo-se deitar sobre Coimbra. E chegou i o primeiro dia de Março, em Cooresma, e fez muito estrago, e o arravalde todo foi estragado. E derribarom as casas, e filharom muito pam e muito vinho e muito azeite, e danarom todo o campo, que era semeado de pam novo, e cortarom todos os olivaes, também d'aaquem como d'aalem. E chegou i dom Afonso Guedelha, que se chamou rei de Leom em outro tempo, padre de dom Joham. O ifante, quando soube que seu padre jazia sobre Coimbra, alçou-se de Guimarães e chegou a Sam Paulos com o conde dom Pedro, seu irmão, que entom era exerdado do reino, e com outros ricos homees e com gram poder de cavalaria, e jouve i tres dias, per trégua que houve antre seu padre e ele. Passou-se seu 
como testemunha e partícipe dos acontecimentos, que têm a cidade como cenário $^{37}$. O arrabalde, o mosteiro de São Paulo, o rio, a ponte, o mosteiro de São Francisco e o mosteiro de Santa Cruz desenham o âmbito - urbano do conflito. $\mathrm{O}$ espaço sistematiza as ações de tal maneira que a narrativa se projeta em um plano fixo e estável. O registo imortaliza por escrito um acontecimento pretérito que ainda hoje se pode reconstruir espacialmente.

O último dos textos, o capítulo DCCXIX da Crónica de Espanha de 1344 , é o mais rico ${ }^{38}$. A sua escrita situa-o cronologicamente depois dos anteriores $^{39}$; mas também foi deixado para o fim porque algumas das suas características no que se refere ao tratamento do espaço no relato já foram aqui analisadas. Por exemplo, e tal como na Vida, a ausência de datações faz com que o referente espacial marque o ritmo do relato e indique a sua progressão. O escrito começa por listar os lugares que D. Dinis povoou, cercou e lavrou ${ }^{40}$. A representação gráfica destes lugares num mapa indica

padre aalem per ua barca, e em outro dia, de gram manhãa, tornou, e quis entrar a vila pela ponte, e houvi i gram peleja. E dom Martim Gonçalves e dom Estevam Gonçalves Leitões deitarom Gonçalo Pirez Ribeiro da ponte ao fundo. E nom pode el rei entrar, e foi pousar a Sam Francisco, e o ifante veio pousar no mosteiro de Santa Cruz, e dali poserom treguas, e alçou-se el rei, e fo-se pera Lixboa» (p. 130 e 131).

${ }^{37} \mathrm{Na}$ Vida e milagres de Dona Isabel também se relata este episódio, mas não se descreve o cerco e também não se narram os acontecimentos que aparecem no Livro de Linhagens. Da mesma maneira, o Livro não fala da intercessão da Rainha para pôr fim ao enfrentamento. Sobre as diferentes versões destes conflitos nos relatos do período MOREIRA, Filipe Alves - ¿Cómo trabajaban los cronistas portugueses? Los relatos de la guerra civil de 1319-1324 in Cahiers d'Études Hispaniques Médiévales 36 (2013) (no prelo).

${ }^{38}$ O capítulo DCCXIX em LINDLEY CINTRA, Luís Filipe - Crónica Geral de Espanha de 1344, 4, Lisboa: Academia Portuguesa de História/Imprensa Nacional-Casa da Moeda, 2009 ( $2^{\text {a ed. }), ~ p . ~ 243-259 . ~}$

${ }^{39}$ Sobre o texto, a sua datação e a sua autoria, LINDLEY CINTRA, Luís Filipe - Crónica Geral de Espanha de 1344, 1 (Introdução), Lisboa: Academia Portuguesa de História/ /Imprensa Nacional-Casa da Moeda, 2009 (2a ed.) e KRUS, Luís - Crónica Geral de Espanha de 1344 in LANCIANI, Giulia e TAVANI, Giuseppe (coord.) - Dicionário de Literatura Medieval Galega e Portuguesa, cit., p. 189 e 190. Tal e como no caso do Livro de Linhagens, edita-se uma refundição posterior, mas o relato do reinado de D. Dinis considera-se da autoria do Conde de Barcelos (cf. LINDLEY CINTRA, Luís Filipe - Crónica Geral de Espanha de 1344, 1, cit., p. CXXXIV-CXL).

${ }^{40}$ «Este pobrou muytos logares e villas en Portugal e outras cercou muy bem. Primeiramente: Miranda; e Vinhaaes; e Villa Frol; e Alfandega; e Mirandela; e Villa Nova de Cerveira; e Villa Real; e Guimarãaes; e Bragaa; e o castello do Sabugal; e enadeo en Castello Rodrigo; e Moura; e Serpa; e enadeo e Juromenha; e lavrou Olivença; e o Alandroal; e Veiros; e Mõforte; e o Açumar; e Evoramõte; e Arrayollos; e Noudar; e Villa Viçosa; e Borva; e o 
uma clara tentativa de fortalecer a área nortenha do reino e a fronteira meridional. Os conflitos fronteiriços com Castela determinaram a presença do rei em localidades como Guarda, São Martinho de Angueira ou Elvas ${ }^{41}$; mas o narrado situa-se sobretudo na área litoral. Coimbra tem menos peso que nos textos anteriores, e para além de Lisboa, Santarém, Porto, Guimarães e Leiria, aparecem citados Pombal, Viseu, Montemor-o-Velho, Alverca, Albogas e os castelos de Feira e Gaia. Os lugares de Pinheiro de Ázere ou Santa Comba Dão estão relacionados com os problemas do Conde de Barcelos e com a sua partida do reino ${ }^{42}$. Nos movimentos do rei aparecem Lisboa e Santarém como principais polos ${ }^{43}$.

Ao contrário do que sucede no Livro de linhagens, na Crónica de 1344 o cerco de Coimbra não é narrado ${ }^{44}$; mas o escrito faz de outras duas localidades cenários: Albogas e Santarém. No primeiro caso, Lisboa e Santarém estão representadas no conflito através dos seus concelhos ${ }^{45}$. As cidades passam assim a ser entidades vivas, que apoiam ou atraiçoam o monarca.

Redondo; e outras villas e castellos que nos ainda aquy non dizemos, assy en Portugal como no Algarve, e outras muytas benfeitorias que fez» (p. 243).

${ }^{41} \mathrm{Na}$ edição citada p. 245-247.

${ }^{42}$ «E o conde era muyto amado dos filhos d'algo e ajuntou tãtos vassalos e amigos que forom mais que os outros e esperou en huu logar que ha nome Pinheiro d'Azer, a par de Sancta Cõoba Dãa, acerca de tres domaas, ataa que veo o iffante dom Affonso de Lixboa por partir a cotenda» (p. 253).

${ }^{43}$ Na narração da morte de D. Dinis segue-se o percurso Lisboa-Santarém, com paragem em Alberca: «E, feyto isto, fosse o iffante pera Coimbra e el rey dom Denis pera Lisboa e hy steve ataa despois do Sam Miguel. E depois, tornãdosse pera Santare, deulhe hua door no caminho, no logar que chamã Alverca, e jouve hy doente alguus dias. (...) E el rey foisse en amdas pera Sanctarem e steve hy enfermo ataa VII dias de Janeiro, fazendo sempre muytas esmolas aos pobres e outrossi muyto be por amor de Deus. E, acabado este tempo, morreo» (p. 259).

${ }^{44}$ «E entõ levãtousse o iffante de sobre Guimarãaes e foisse pera Coimbra. E, ante que la chegasse dous dias, o conde dom Pedro e outros fidalgosque hy erã d'ambas as partes fezerom com el rey que ouvesse tregoas cõ o iffante. E entom veo o iffante cõ a sua madre a Coimbra. E o conde e os outros nobres homes trouxerom pleitesia cõ el rey» (p. 254).

${ }^{45}$ «E el rey, quando soube como viinha, sayo de Lixboa e chegou ataa as Albogas. E o cõcelho de Lixboa disselhe que hiria com elle e que o serviria como a seu senhor. E el rey disse que lho gradecia muyto e forõsse cõ elle. E, quando chegarõ aas Albogas, pedio o cõcelho de Lixboa a el rey logar en que pousassem e elle mãdoulho dar. Mas elles nõ quiserom ally pousar e foronse apousentar aalem de $\mathrm{h} \sim$ ua ponte que hi sta, a par do iffante. E outrossi viinha cõ elle o concelho de Santare. E el rey mandou-lhe dizer e afrontar que non quisesse viir a sua villa sem sua võotade e que se tornasse logo. E pera esto mandou la a reya» (p. 257 e 258). 
Os elementos estáticos que atuavam como referências transformam-se em personagens do relato. Quando Santarém é escolhido como cenário, a cidade torna-se palco dum espetáculo narrado, e as suas ruas, edifícios e monumentos desenham um marco espacial que facilita a compreensão das ações $^{46}$. O espaço desempenha, portanto, do ponto de vista narrativo, várias funções. Contudo, são os acontecimentos escolhidos para serem narrados os que determinam que lugares aparecem no relato, e assim criam uma imagem histórica do reino; uma representação política do território baseada nos acontecimentos históricos.

Normalmente, os historiadores trabalham com fontes documentais que fornecem dados dispersos. Os constantes movimentos dos membros da família real na Idade Média, por exemplo, são reconstruidos a partir de documentos que situam essas personagens em determinados lugares. Com esses dados criam-se itinerários aproximados; e a partir deles são definidos os lugares mais visitados, e analisados os motivos de uma presença ou um deslocamento. Acontece, porém, que as fontes documentais medievais conservadas são escassas, e o relato que se cria com elas contem vazios involuntários. No entanto, com as fontes narrativas escritas na altura em que os factos aconteceram, ou pouco depois, a informação chega ao historiador no sentido inverso: a aparição do nome duma localidade é intencional; os motivos e as consequências dos atos são direta ou indiretamente expostos; a interpretação dos sucessos, da sua importância, da sua ordem e do seu significado, foi feita pelo autor do relato. Uma fonte narrativa deste tipo fornece dados conscientes, e desta maneira cria uma imagem do território concreta. Mesmo se o objetivo principal do autor não fosse o de representar no seu escrito o reino, tinha que fazê-lo para situar nele as ações. Assim, dava forma a um mapa abstrato que hoje, quando analisado e representado, revela imagens que nos permitem conhecer melhor o território pretérito.

${ }^{46}$ «E, depois que comerom, começarom de pelejar os do iffante e os da villa cõ os del rey e de cada hua parte aderençarõ pera honde el rey stava, per aquella rua mayor que vay do alcacer pera o pelourinho. Viinhaã os do iffante e acharõ os del rey tam espessos que nõ podiã hir por diante ne atras e, veedo que nõ podiã hi tyrar prol, começarõ de se hir sayndo contra San Nicolaao honde pousava o conde. E veerom a elle por tres partes» (p. 259). 